\title{
Modulation of Taste Affect by Hunger, Caloric Satiety, and Sensory-Specific Satiety in the Rat
}

\author{
KENT C. BERRIDGE \\ Department of Psychology, The University of Michigan
}

Human judgements of the pleasure of sweetness have been reported to be modulated by caloric hunger, satiety, and sensory-specific satiety. This study examined both hedonic and aversive facial/somatic reactions to taste in the rat, in order to confirm the relation of hunger and satiety to taste affect, and to assess whether affective modulation depends upon the cognitive factors that mediate human self-interpretation of affect.

In the first experiment, the affective reactions of rats to sweet, bittersweet, and water tastes were assessed in five states of caloric hunger or satiety. Caloric satiety reduced positive hedonic reactions below normal levels. Conversely, 48 -h food deprivation (but not 24-h deprivation) increased hedonic reactivity. Hedonic enhancement by hunger was not restricted to sweet tastes, but also extended to the palatability of water. Only the hedonic reactions to taste were changed by hunger or satiety: taste aversion was not altered.

The second experiment compared the magnitude of affective change during sensory-specific satiety and caloric satiety. Taste-reactivity elicited by sucrose solution or milk was assessed after satiating meals of each of those foods. Sensoryspecific satiety further reduced hedonic reactions below the level achieved by caloric satiety alone. Both for caloric satiety and for sensory-specific satiety changes in affect were restricted to positive hedonic reactions: no increase in aversion accompanied the hedonic decrements.

These results confirm that taste affect is modulated during caloric hunger, caloric satiety, and sensory-specific satiety. In addition they indicate that the modulation of taste affect by hunger and satiety is confined to the positive limb of the two dimensions (hedonic vs. aversive) of palatability.

\section{INTRODUCTION}

Cabanac's (1971) introduction of the term "alliesthesia" marked an important step for the physiological psychology of motivation. This term refers to a change in the affective perception of an unchanged stimulus caused by fluctuations in the physiological state of the perceiver (Cabanac, 1971). Cabanac et al. (1971) asked individuals to rate the pleasantness of a sweet solution, and found that sweetness became less pleasant after they had ingested glucose syrup (and that this "negative alliesthesia" was prevented by long-term dieting). Building on the tradition of Young (e.g. 1948, 1959), Cabanac and his colleagues thus re-introduced hedonics into motivational theory in a way that could be linked objectivcly to physiology. Their

This project was supported by National Institutes of Health Grant NS 23959

I am grateful to Darlene Tansil for assistance in these experiments.

Address correspondence and reprint requests to: K. C. Berridge, Department of Psychology, Neuroscience Building, University of Michigan, 1103 E. Huron Street, Ann Arbor, MI 48104, U.S.A. 
studies showed that the elicited affective state could be systematically changed by manipulating physiological conditions (Cabanac \& Fantino, 1977; Cabanac, 1979; Fantino, 1984). Although failures to find gustatory alliesthesia in humans after glucose loads have been reported under some conditions (e.g. Moscowitz et al., 1976; Stellar, 1982), many replications of the phenomenon now exist (see Fantino, 1984, for review). Support for the modulation of taste affect by caloric state has come also from animal studies of the effect of glucose loads upon intake (e.g. Bedard \& Weingarten, 1989) and upon the electrophysiological responses of gustatory neurons that respond to sweet taste (e.g. Giza \& Scott, 1987).

Beyond the effect of caloric state upon taste palatability, Rolls and Rolls and their colleagues have documented an additional form of hedonic modulation, which they have called sensory-specific satiety (e.g. Rolls, et al., 1981; Rolls, et al., 1983; Rolls, 1985; Hetherington, et al., 1989). In this phenomenon, after consuming a meal of a particular food, humans report that the palatability of that food declines more than does the palatability of other foods. Sensory-specific satiety has been linked to the stimulating effect of meal variety upon food intake (Le Magnen, 1956; Treit, et al., 1982; Clifton, et al., 1987). This phenomenon has been supported also by electrophysiological studies of hypothalamic neurons that respond to the incentive value of foods (e.g. Rolls et al., 1986).

\section{Affect and Introspection}

Direct demonstrations of the changes in taste affect that are induced by caloric state or sensory-specific experience have come primarily from studies in which humans have been asked to rate their subjective perception of the pleasantness of tastes. What better way to assess hedonic states accurately than to ask humans how they feel? Yet studies that have examined the capacity of human introspection to monitor changes in psychological processes such as affect have concluded that introspection can be surprisingly inaccurate concerning those processes (see Nisbett \& Wilson, 1977, for review).

A human subject often fails to note changes in his or her own opinions or reactions that can be demonstrated by behavioral or physiological measures (e.g. Cohen \& Zimbardo, 1969; Bem \& McConnell, 1970). When asked to report about what they have experienced and why they have responded in a particular way, human subjects in many situations fail to report factors that can be shown to have influenced their behavior (e.g. Schachter \& Singer, 1962; Nisbett \& Schachter, 1966). Perhaps of greatest concern regarding the accuracy of reports of affective modulation, in certain situations humans may "recall" mental processes (e.g. attitudes) that they can be shown never to have held (e.g. Goethals \& Reckman, 1973).

Introspection involves the active construction or inference of current beliefs and feelings based upon a multitude of factors, rather than a direct "readout" of underlying thought or emotion (Nisbett \& Wilson, 1977). In spite of our veridical experience of conscious awareness, in other words, introspection provides a less sensitive and less accurate index of the occurrence of some psychological processes than is provided by behavioral and physiological measures!

Regarding appetite and food palatability, Booth (1987) has pointed out the possibility that ratings of motivational factors that seem to be distinct may sometimes reflect only the same fundamental factor that has been described differently in response to different questions. Subjective ratings of different motivational factors, 
(a)
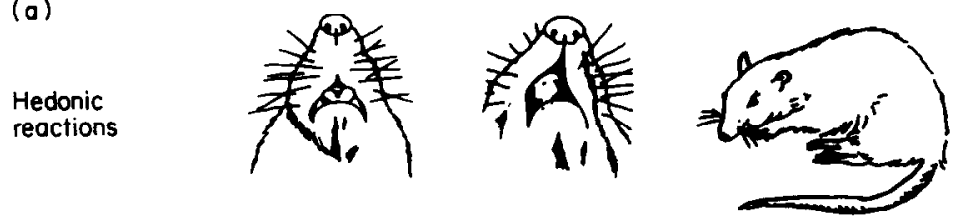

(b)

Aversive reactions

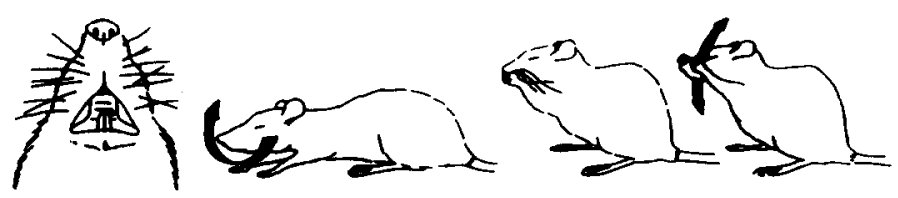

FIGURE 1. Affective reactions to taste. (a) Positive hedonic reactions are elicited by sucrose and other palatable tastes. Hedonic reactions include rhythmic tongue protrusion, lateral tongue protrusion, and paw lick. (b) Aversive reactions are elicited by quinine and other unpalatable tastes. Aversive reactions include gape, headshake, face wash, and forelimb flail.

such as the pleasantness of eating a food, the strength of the desire to eat, and the intensity of hunger sensations, covary together so highly as to raise the suspicion that these "separate reports" may not assess different underlying processes. The different ratings instead might be descriptions of the same psychological factor(s), which the subject interprets in different terms depending upon the question, and which is then elaborated and expressed using different concepts (Booth, 1987). This argument raises the problem of purity in interpreting human reports of affective changes. Can one be sure that a change in a subjective rating of food pleasantness during hunger or satiety is not simply a restatement of a change in the desire to eat?

\section{Affective Reaction without Introspection}

One way of corroborating the affective purity of "palatability shifts" is to examine them through a measure that does not require precise self-interpretation and linguistic elaboration. Such a measure might be applied to the affective processes of animals as well as of humans. How can we identify such a measure for affect? Since the desire to eat is controlled by many factors besides taste affect, a specific measure of taste affect cannot be validated simply by whether it predicts subsequent intake. The propensity to ingest is not identical to taste affect (see Berridge \& Valenstein, 1991). Even shortexposure preference tests or sham-feeding measures more directly assess the propensity to ingest a particular taste than they do the pleasure or aversion produced once the taste is ingested. Changes in the propensity to ingest can be mistaken for changes in affect by such measures regardless of whether taste affect has actually changed. A specific measure of affective change should be able to dissociate affect (pleasure and aversion) from appetite (the propensity to ingest), at least under certain conditions.

Affective taste reactivity patterns (Grill \& Norgren, 1978) provide a measure that can assess taste affect specifically (Figure 1). The natural affective reactions of rats are highly sensitive to properties of taste palatability (Grill \& Berridge, 1985). Although reactions to taste are influenced also by sensorimotor fatigue and arousal factors, in most cases it is possible to separate such factors from affect through analyses of the 
pattern of responding (e.g. Berridge, et al., 1989). Pattern analyses of taste reactivity provide the most adequate technique currently available for measuring basic evaluations of taste pleasure or aversion without self-report.

Taste affect is usually correlated with preference, but in certain situations affective taste reactivity can be dissociated from the propensity to eat. For example, without altering hedonic reactions, the propensity to ingest can be increased by electrical stimulation of the lateral hypothalamus (Berridge \& Valenstein, 1991) or reduced by depletion of brain dopamine projections (Berridge et al., 1989). In both cases, taste-elicited reactions remain sensitive to factors that normally influence palatability. Conversely, different affective reactions may be elicited by tastes that are equally preferred, so long as a constant balance between hedonic and aversive reactions is kept (Berridge \& Grill, 1984). These dissociations between intake and affective reactions indicate that when appetite and taste affect diverge, hedonic and aversive reaction patterns track taste affect specifically rather than tracking the propensity to ingest. Other manipulations of appetite, on the other hand, alter both affective reactions to taste and intake, and can be viewed as controlling feeding via an affective route (see Grill \& Berridge, 1985, for review). Studies of taste reactivity during satiety or hunger have indicated that taste hedonic reactions are indeed diminished by gastric loads of glucose (Cabanac \& Lafrance, 1989; 1990), and enhanced by $48 \mathrm{~h}$ of food deprivation (Breslin \& Grill, 1988).

In this experiment, taste reactivity measures were used to compare changes in taste affect under a number of caloric depletion and satiety conditions. The specificity of sweetness as a gustatory target for affective changes, and the relative contribution of hedonic versus aversive modulations to changes in affect also were examined. In a second experiment, the ability of sensory-specific satiety to further modulate taste affect was examined, and the magnitude of the affective change produced by sensoryspecific satiety was compared to that of caloric satiety.

\section{EXPERIMENT 1}

\section{Methods}

\section{Subjects}

Twenty-three female rats (Sprague-Dawley, 250-350 g) were anesthetized with ketamine $(100 \mathrm{mg} / \mathrm{kg})$ and xylazine $(10 \mathrm{mg} / \mathrm{kg})$. Each rat was implanted with two chronic oral cannulae for mouth infusion in order to permit later taste reactivity testing. Oral cannulae (constructed of heat-flared PE 50 tubing, teflon anchor, and 23 ga steel external connector) entered the mouth lateral to the first maxillary molar, ascended within the zygomatic arch, and were anchored to the dorsal skull with bone screws and acrylic cement.

\section{Taste stimuli and rationale}

The aim of this experiment was to ascertain the relation of caloric deprivation and satiety to the affective evaluation of sweet tastes. Three tastes of different sweetness were used: two were pure sucrose solutions ( 4 and $17 \% \mathrm{w} / \mathrm{v}$ ), both of which are highly preferred by rats to water. Oral infusions of sucrose solutions tend to elicit only positive hedonic reactions from normal rats, and few or no aversive reactions. Since it was of interest to know whether caloric hunger or satiety modulated aversive 
palatability, as well as positive taste pleasure, the third sweet taste carried an added aversive component. This taste was a "bittersweet" compound of sucrose and quinine $(7 \%$ sucrose, $0.01 \%$ quinine $\mathrm{HCl})$, which is chosen by rats in roughly equal proportion to the lower sucrose concentration in preference tests (Young \& Schulte, 1963). It also was of interest to know whether the relation of hunger and satiety to taste affect was specific to tastes that are sweet or likely to have a caloric content. Distilled water was used in order to provide a taste that was not sweet and that had no caloric component or cue.

\section{Physiological conditions}

The palatability of each taste was assessed by taste reactivity during two caloric hunger conditions and during two caloric satiety conditions, and was compared to its "normal" baseline. Normal baseline was taken to be reactivity after free access to chow pellets and water (for at least $48 \mathrm{~h}$ prior to testing). The relation of taste affect to caloric hunger was assessed after 24 and $48 \mathrm{~h}$ of food deprivation (water was available throughout). Satiety was induced by either a "voluntary" or "involuntary" procedure that ended $10 \mathrm{~min}$ before testing. Voluntary satiety was induced by providing a $1 \mathrm{~h}$ meal (unlimited quantity) of a preferred cereal mash (Gerber's Mixed Baby Cereal). Prior to the first test in this condition, rats were given the opportunity to eat mash for $1 \mathrm{~h}$ on 3 successive days in order to eliminate neophobia. "Involuntary" satiety without oral consumption was induced by a gastric intubation of $10 \mathrm{ml}$ of a mixture of equal parts sweetened condensed milk and water. Intubation was delivered via an infant feeding tube that was passed gently down the esophagus of the hand-held rat. Prior to testing in this condition, rats were given intubations of ascending volume (6, 8 and $10 \mathrm{ml}$ ) on 3 successive days in order to habituate to gastric distension and to the handling procedure.

\section{Taste reactivity test procedure}

Taste reactivity tests were carried out during the light portion of the 14:10 light/ dark cycle. Each rat was tested only once per day. Tastes were administered in random order. For a given taste, all physiological conditions were tested before moving to the next taste. Physiological conditions also were tested in random order, except that the 24- and 48-h food deprivation tests were always run on consecutive days (in order to minimize the number of deprivation experiences).

In a taste reactivity test, a rat's oral cannula was connected to a delivery tube (PE 50 tubing with PE 10 nozzle), and the rat was allowed to habituate to the test chamber for $5 \mathrm{~min}$. The transparent floor of the chamber was suspended over a mirror, which reflected a view of the face and mouth into the close-up lens of a video camera. The trial lasted $30 \mathrm{sec}$, during which the delivery tube infused $0.5 \mathrm{ml}$ of the taste solution into the rat's mouth at a constant rate. Reactivity to the taste was videotaped for later slow-motion analysis.

\section{Video analysis}

An observer who was blind to the physiological condition of the rat scored the videotaped record for the occurrence of positive hedonic and aversive reactions. Positive hedonic reactions were the following; lateral tongue protrusions (nonrhythmic) lasting about $160 \mathrm{msec}$; rhythmic tongue protrusions along the midline with a cycle length of roughly $160 \mathrm{msec}$; and paw licking. Aversive reactions were the following: gapes: large openings of the mouth and jaw lasting about $125 \mathrm{msec}$; chin 
rubbing: bringing the chin in direct contact with the floor and projecting the body forward; face washing: either a single wipe with the paws over the face or a bout of several wipes; forelimb flails: shaking of the forelimbs back and forth; paw treading: forward and backward movement of the forepaws in synchronous alternation; rapid headshaking: rapid lateral vibration of the head and neck. Continuous rhythmic tongue protrusions were scored in bouts of up to $2 \mathrm{sec}$. All other actions were scored each time they occurred.

\section{Results}

\section{Hedonic reactivity}

Physiological caloric state was a powerful determinant of hedonic reactions elicited by tastes (two-way ANOVA) $[F(4,20)=7 \cdot 20, p<0.01]$. The effects of physiological state could be divided into hedonic suppression by caloric satiety and hedonic enhancement by caloric deprivation.

Negative alliesthesia of caloric satiety. Positive hedonic reactions were suppressed by the voluntary satiety resulting from $1 \mathrm{~h}$ free consumption of cereal mash $[F(1,18)=5 \cdot 10, p<0 \cdot 05]$. Rats consumed an average of $21 \pm 6 \mathrm{~g}$ of mash prior to testing. Hedonic reactivity was also suppressed at least as strongly by involuntary caloric satiety, induced without oral consumption by direct gastric intubation of $10 \mathrm{ml}$ sweetened milk $[F(1,18)=5 \cdot 36, p<0 \cdot 05]$. It should be noted that although the volume of mash ingested was greater than the volume of intubated milk, mash consumption was distributed over $1 \mathrm{~h}$ whereas milk was intubated over $20 \mathrm{sec}$. This may account, in part, for the potency of intubation in suppressing hedonic reactions. For each sweet taste [ $4 \%$ sucrose (Figure 2), 17\% sucrose (Figure 3), and the sucrose/quinine mixture (Figure 4)] hedonic reactions were suppressed below baseline by both mash consumption and intubation (LSD tests, $p<0.05$ in each case). Positive hedonic reactivity to distilled water was not suppressed significantly by either type of satiety, compared to normal baseline. Hedonic reactivity to water was suppressed by both types of satiety, however, when compared to the hedonic levels elicited by water after either $24 \mathrm{~h}$ (LSD, $p<0.05$ each) or $48 \mathrm{~h}(p<0.01$ each) of food deprivation (Figure 5).

Positive alliesthesia of caloric deprivation. Hedonic reactions were enhanced above baseline levels to the same tastes overall by $48 \mathrm{~h}$ food deprivation $[F(1,18)=5 \cdot 54, p<0 \cdot 05]$, but not by $24 \mathrm{~h}$ food deprivation $[F(1,18)=0 \cdot 15]$. Differences across tastes in the effect of food deprivation were seen in post hoc comparisons. Positive hedonic reactivity to the sucrose/quinine mixture was enhanced after $48 \mathrm{~h}$ deprivation (LSD, $p<0.05$ ) but not after $24 \mathrm{~h}$ deprivation (Figure 4 ) just as the two-factor ANOVA had indicated. Hedonic reactivity to pure sucrose solutions, which lacked a bitter component, was not enhanced beyond baseline levels by either period of deprivation, suggesting the possibility that a "positive ceiling" of pleasure or reactivity performance had been reached for these stimuli (Figures 2 and 3). Hedonic reactivity to distilled water was not significantly elevated above baseline by food deprivation but, as described above, was elevated above the levels of hedonic reactivity shown to water during satiety conditions (Figure 5). 


\section{Aversive reactivity}

Aversive reactions (gapes, chin rubs, headshakes, forelimb flail, face wipes, paw treads) were not affected by changes in physiological state $[F(4,20)=1.92]$, although they were sensitive to taste quality $[F(3,15)=4.06, p<0.05]$. Aversive reactivity remained unaffected by physiological state even for the sucrose/quinine mixture (Figure 4), which included an aversive bitter component that could in principle have been manipulated either upwards or downwards. The only modification of aversion observed in this experiment was an elicitation of strong aversive reactivity on two out of 92 intubation trials (once in response to distilled water and once to the sucrose/ quinine mixture). This aversion was atypical, however, and did not significantly affect the group statistics.

\section{Discussion}

These results documented the modulation of taste affect after changes in physiological caloric state. Hedonic reactivity was reduced below normal levels by caloric satiety ("negative alliesthesia" in Cabanac's terms), and was cnhanced above normal levels by $48 \mathrm{~h}$ caloric deprivation ("positive alliesthesia"). Although both enhancement and suppression of hedonic reactions were obtained, the suppression effect of satiety appeared to be more potent than the enhancement effect of hunger. Hedonic suppression was produced for all sweet tastes by consumption of a cereal

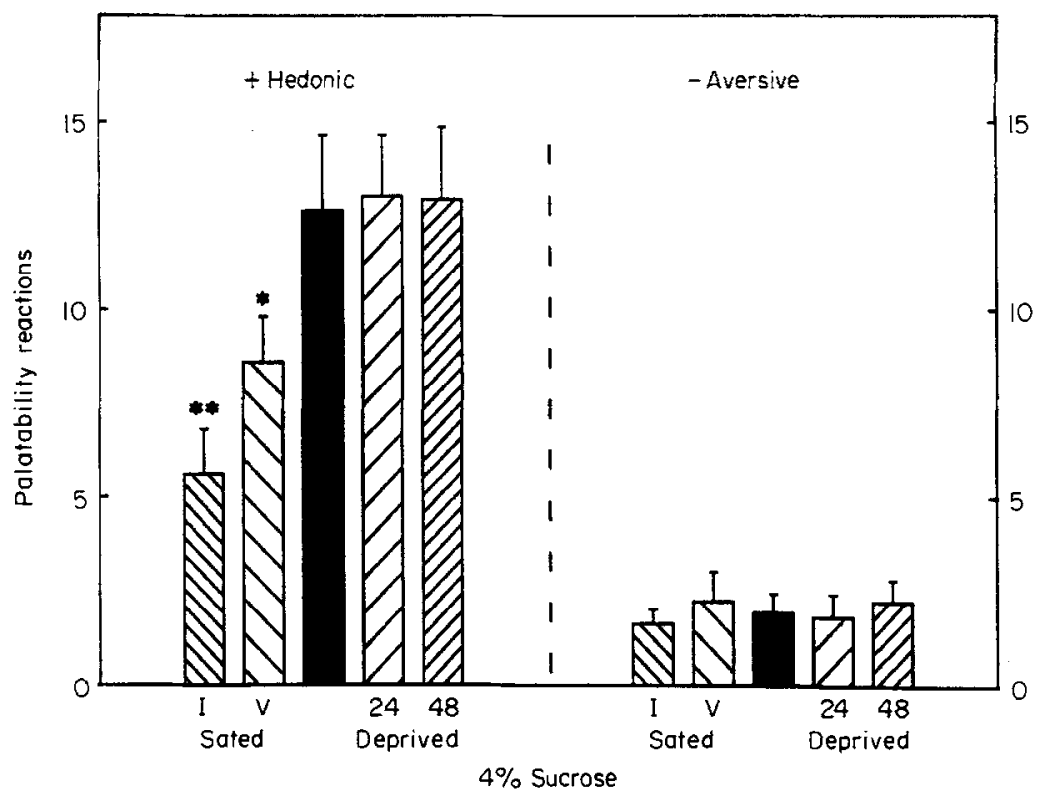

Figure 2. Experiment 1. Changes in affective reactions to $4 \%$ sucrose produced by hunger and caloric satiety. Hedonic and aversive reactions to $4 \%$ sucrose in five caloric conditions $( \pm S E M)$ : involuntary satiety after intubation (I), voluntary satiety after a $1 \mathrm{~h}$ mash (V), normal baseline condition ( $\square$ ), hunger after $24 \mathrm{~h}$ food deprivation (24), and hunger after $48 \mathrm{~h}$ food deprivation (48). Hedonic reactions are reduced significantly from baseline by satiety that is induced either by voluntary consumption or by involuntary intubation. Aversive reactions are not affected $\left(*\right.$ denotes significant difference from baseline, $p<0.05 ;{ }^{* *} p<0.01$ ). 


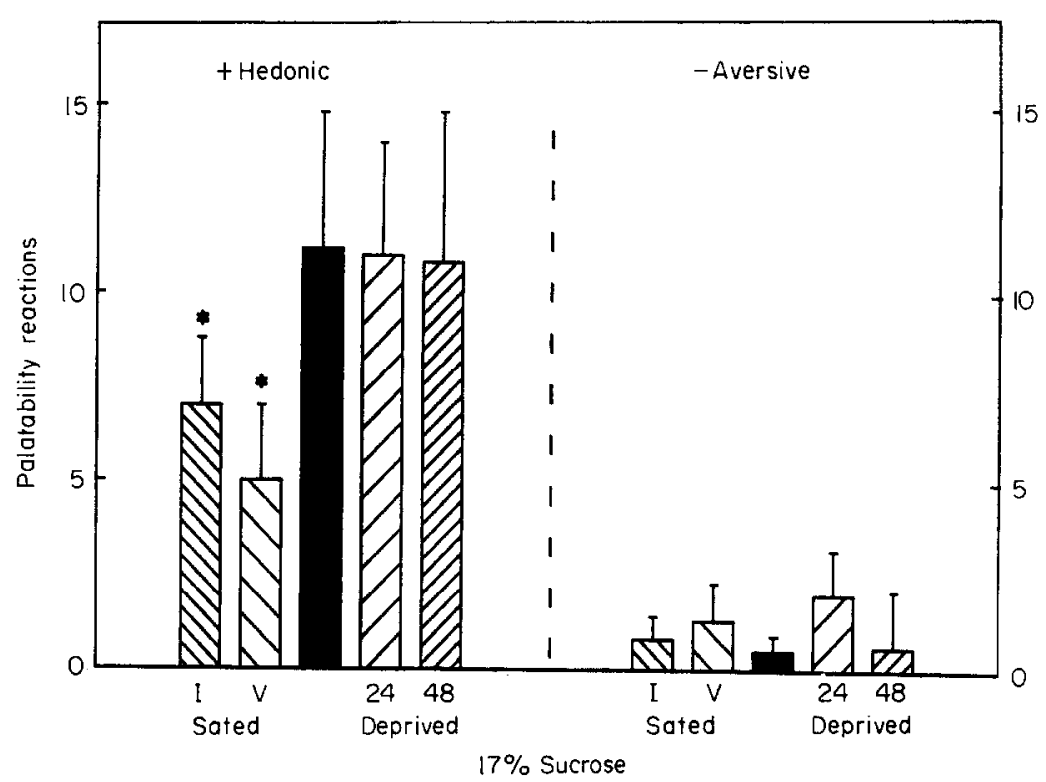

FIGURE 3. Experiment 1. Changes in affective reactions to $17 \%$ sucrose produced by hunger and caloric satiety. Hedonic and aversive reactions to $17 \%$ sucrose in the five caloric satiety, baseline, and deprivation conditions. Hedonic reactions are reduced from baseline by satiety that is induced either by voluntary consumption or by intubation. Aversive reactions are not affected.

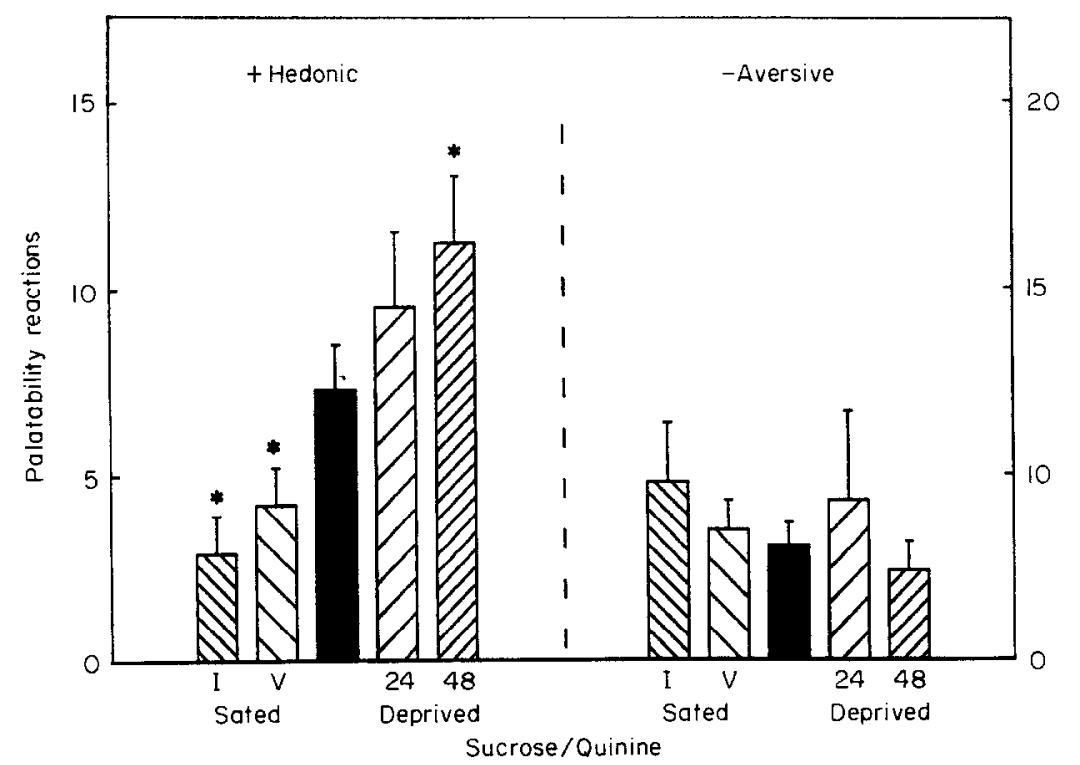

FIGURE 4. Experiment 1. Changes in affective reactions to a sucrose/quinine mixture produced by hunger and caloric saticty. Hedonic and aversive reactions to sucrose/quinine in the five caloric satiety, baseline, and deprivation conditions. Hedonic reactions are reduced significantly below baseline by caloric satiety conditions, and are enhanced significantly above baseline by caloric hunger after $48 \mathrm{~h}$ food deprivation. Aversive reactions are not affected. 


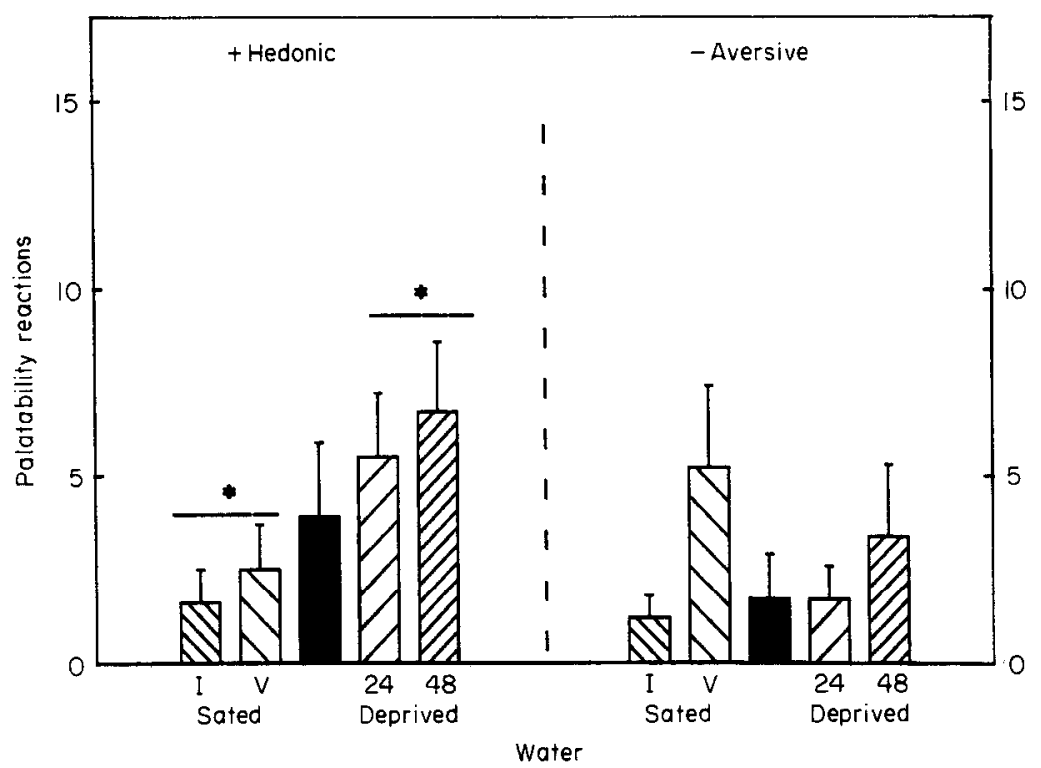

FIGURE 5. Experiment 1. Changes in affective reactions to water produced by hunger and caloric satiety. Hedonic and aversive reactions to watcr in the five caloric satiety, baseline, and deprivation conditions. Hedonic reactions are suppressed by caloric satiety compared to hedonic levels elicited after caloric deprivation. Bars under different starred lines differ significantly from each other $(p<0 \cdot 05)$. Aversive reactions are not affected significantly.

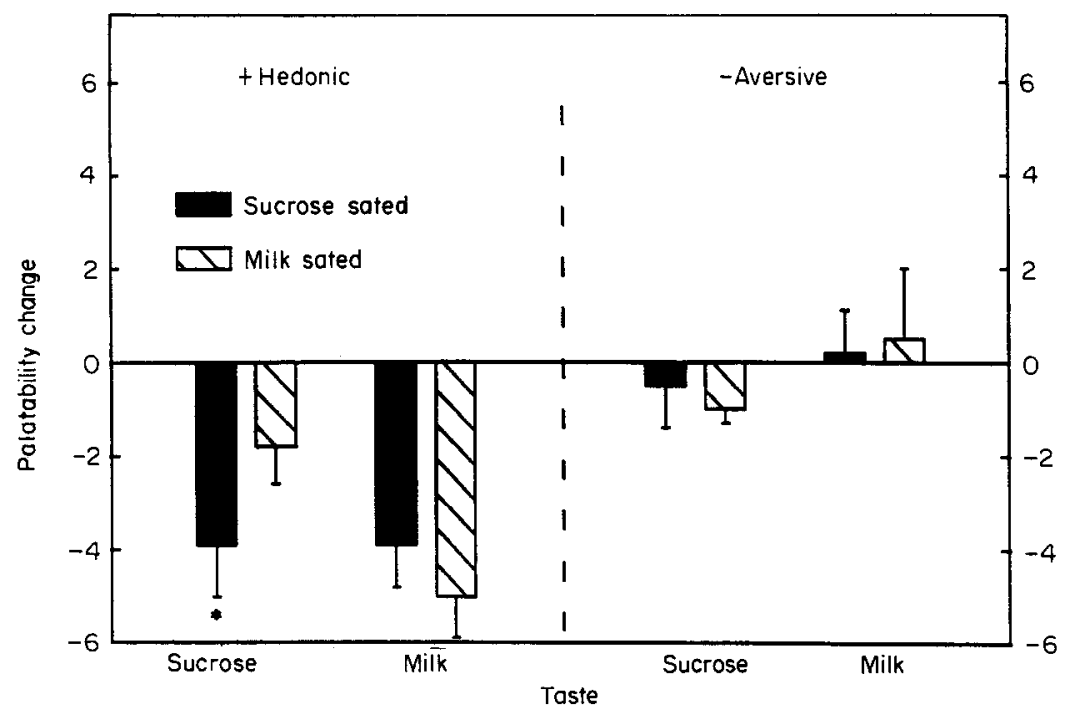

FIGURE 6. Experiment 2. Relative effects of caloric satiety and sensory-specific satiety on affective reactions. Bars show the change in hedonic and aversive reactions induced by satiety (relative to normal baseline reactivity). Hedonic reactions to the taste of sucrose or milk are suppressed by prior satiation upon either food, but are suppressed significantly more for sucrose after satiation on sucrose than after satiation on milk (* denotes sensory-specific satiety difference in reaction to same taste, $p<0.05$ ). Aversive reactions are not affected. 
meal and by gastric intubation of a liquid diet. Hedonic enhancement was produced to a significant degree, however, only by a $48 \mathrm{~h}$ period of food deprivation. Although there was some indication of a very weak enhancement of positive hedonic reactions at $24 \mathrm{~h}$, this trend was not significant. It is possible that $24 \mathrm{~h}$ food deprivation might produce a stronger hedonic enhancement under different conditions (for example, during the dark phase of the light/dark cycle), but these results suggest that hedonic potentiation at best is very weak at $24 \mathrm{~h}$ relative to $48 \mathrm{~h}$ of food deprivation. The significant enhancement of positive hedonics by $48 \mathrm{~h}$ food deprivation, furthermore, was missing for pure sucrose tastes that began with high hedonic baselines in the normal ad libitum condition, suggesting that caloric hunger may not be able to enhance palatability beyond a certain level. It should be noted in contrast that the hedonic response to pure sucrose solutions can be enhanced above normal baseline levels by manipulations such as benzodiazepine administration (Berridge $\&$ Treit, 1986).

Caloric alliesthesia was highly specific to the positive hedonic dimension of palatability. Aversive evaluations of taste palatability were not changed by satiety or hunger conditions. The dissociation of hedonic/aversive changes is not likely to be due to differences in response sensitivity. In general, aversive reactions are not less sensitive than hedonic reactions to changes in palatability: other manipulations have changed aversion even when hedonic reactions remained constant (e.g. Berridge \& Grill, 1983). These data support the notion that hedonic taste palatability is evaluated separately from taste aversion (Berridge \& Grill, 1983, 1984). They also indicate that hunger and caloric satiety both relate directly to the hedonic dimension of affective processing, and shift the hedonic perception of a taste without altering the aversiveness of that taste (Figure 7). Finally, the stability of aversive reactions (even to the quinine/sucrose mixture) helps to rule out the possibility that response decrements after satiety were due to reduced sensorimotor arousal. An arousal factor would be expected to alter all responses-not just hedonic ones.

Although the effect of caloric alliesthesia appeared to be specific to a single dimension of palatability, it was not specific to a taste quality. The strongest alliesthesia was seen for sweet tastes, but caloric state exerted an effect even upon the hedonic response to water.

\section{EXPERIMENT 2}

Experiment 1 demonstrated bidirectional changes in hedonic palatability caused by satiety and by hunger. The second experiment was intended to assess the relation of sensory-specific satiety to taste reactivity, and to compare this relation to that of caloric satiety.

\section{Method}

Subjects

Eleven naive female rats were implanted with oral cannulae as in Experiment 1. Food pellets and water were always available. In addition, each rat was given free access to two attractive liquid foods: milk (1\% milkfat, $70 \%$ lactose reduced) and $0.3 \mathrm{M}$ sucrose. These stimuli were chosen to be roughly similar in caloric content. Free access to each was provided for 1 week (fresh daily) prior to the experiment, in order 


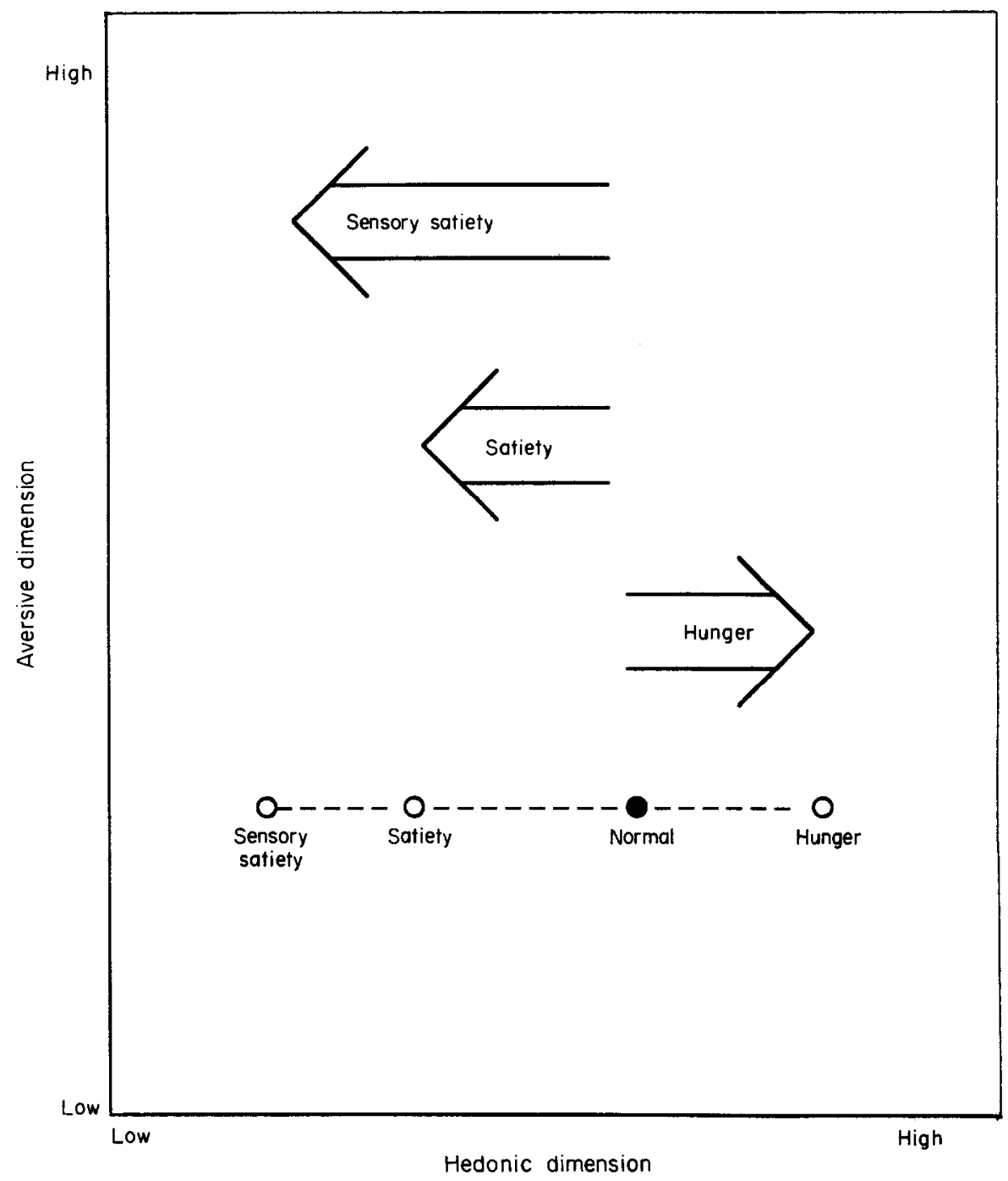

FIGURE 7. Unidimensional changes in taste affect produced by hunger, caloric satiety and sensory-specific satiety. Affective changes are portrayed in a two-dimensional affective space: the vertical dimension represents the aversive continuum, and the horizontal dimension represents the positive hedonic continuum. Arrows show the affective shifts hypothesized to result from caloric hunger $(48 \mathrm{~h})$, caloric satiety, and from sensory-specific satiety. Shifts are in the hedonic dimension only, and aversion remains unchanged (the hedonic enhancement by hunger is presumed to occur only for tastes that have low to moderate hedonic baselines). An example of alliesthesia for a taste of mixed baseline palatability (i.e. sucrose/quinine mixture; -) is shown by changes in position produced by hunger, satiety, and sensory-specific satiety (O).

that the rats might become thoroughly familiar with the foods. Milk and sucrose were taken away $24 \mathrm{~h}$ before testing began (food pellets and water remained).

Sensory-specific satiety induction

Sucrose and milk both elicit strong hedonic reactions ordinarily. It therefore seemed desirable to induce strong sensory-specific satiety for these foods in order to 
reduce their taste pleasure to a detectable degree. To accomplish this, a rat was allowed to consume an oral infusion of one of those foods until it demonstrated that it was thoroughly sated. In this procedure, the oral cannula of a rat was connected to a tube leading to a syringe pump that delivered either milk or sucrose, before the rat was placed in a test chamber. The syringe pump provided an infusion at a constant rate of $1.7 \mathrm{ml} / \mathrm{min}$. The infusion continued until the rat rejected the infusion either actively (showing an aversive reaction concurrent with ejection of the fluid) or passively (simply allowing the fluid to drip out of the mouth rather than ingesting it). If rejection occurred, the pump was halted for $30 \mathrm{sec}$ and then restarted. If the rat rejected the solution again within $15 \mathrm{sec}$ after the infusion was resumed, the rat was considered to be sated. If rejection was not repeated within $15 \mathrm{sec}$, the infusion was continued until two consecutive rejections were repeated within the $15 \mathrm{sec}$ criterion. Mean consumption to satiety was $32 \pm 6 \mathrm{ml}$ for milk and $29 \pm 4 \mathrm{ml}$ for sucrose.

\section{Taste reactivity test}

Taste reactivity was tested $1 \mathrm{~min}$ after the second rejection criterion had been reached. A new delivery tube was attached to the cannula, and $0.5 \mathrm{ml}$ either of the food on which the rat had been sated or else of the other food was infused into the mouth during $30 \mathrm{sec}$. Reactivity to the taste was videotaped for later analysis. Only one satiation and taste reactivity test was performed per day. The order of food satiety/food test pairs was random. Each rat was also tested with milk and with sucrose in a "normal baseline" condition, in which they were not sated on either food but instead simply placed in the chamber for 20 min prior to testing. Reactivity analysis was performed as for Experiment 1.

\section{Results}

\section{Hedonic reactivity}

Satiating infusions reduced the number of hedonic reactions elicited by the taste of milk or sucrose (Figure 6), regardless of which food the rat had been sated upon $[F(2,20)=9 \cdot 31, p<0 \cdot 02]$ : in other words, caloric satiety suppressed hedonics as in Experiment 1 . In addition to caloric alliesthesia, however, a further degree of hedonic reduction was detected for the taste of sucrose in a sensory-specific fashion (Figure 6). Hedonic reactions to sucrose were suppressed to a greater degree if the rat had recently consumed sucrose to satiety than if it had recently consumed milk to satiety (paired $t$-test, $p<0.02$ ). The hedonic suppression of milk palatability showed a slight sensory-specific trend in the appropriate opposite direction (the hedonic suppression was a slightly more pronounced if the rat had consumed milk), but hedonic reactions to milk were greatly depressed regardless of which food had induced satiety and the sensory-specific trend for milk reactivity was not significant statistically.

\section{Aversive reactivity}

Aversive reactions to milk or sucrose were not increased either by caloric satiety or by sensory-specific satiety. The suppression of positive hedonic palatability described above was not accompanied by a reciprocal change of aversion for any taste.

\section{Discussion}

These results replicate the suppression of hedonic reactions by caloric satiety that was found in Experiment 1. In addition, they show that hedonic suppression may be 
strengthened further by sensory-specific satiety for a food. Sensory-specific satiety reduced the hedonic palatability of sucrose to a level below that achieved by caloric alliesthesia alone. Finally, these data indicate that the affective change produced by sensory-specific satiety is confined to the hedonic dimension of taste palatability, just as is the affective change produced by caloric satiety. Both forms of satiety reduced the hedonic properties of taste without altering taste aversion.

\section{General Discussion}

Taste pleasure was shifted in these experiments both upwards (by caloric hunger) and downwards (by caloric satiety and sensory-satiety). Hedonic suppression was more robust than hedonic enhancement. Hedonic reactions to all tastes were suppressed by satiety manipulations, and the suppressive effects of caloric satiety and sensory-specific satiety appeared to add together. Enhancement of pleasure, by contrast, did not occur for tastes that began above a certain level of initial palatability (e.g. the purc sucrose solutions). For tastes that did show hedonic enhancement during hunger, only the $48 \mathrm{~h}$ food deprivation periods, and not the $24 \mathrm{~h}$ deprivation, enhanced taste pleasure.

\section{Gustatory targets of enhancement by hunger}

The enhancement of hedonic reactivity by $48 \mathrm{~h}$ hunger was strongest for the "bittersweet" sucrose/quinine mixture. Perhaps surprisingly, hedonic enhancement of distilled water was also seen (albeit to a lesser degree) after food deprivation. Shifts in watcr palatability might have been expected to be associated only with thirst (Grill \& Miselis, 1981). One interpretation of the enhancement of water palatability during hunger is that the gustatory focus of caloric positive alliesthesia is not restricted to tastes that carry a "caloric label" such as sweetness. Instead, any taste of moderate palatability might be enhanced hedonically by hunger. If so, this broad gustatory focus of caloric alliesthesia would contrast to the narrow focus of alliesthesia induced by depletion of body sodium, which is restricted to the taste of salt (Schulkin, 1982; Berridge, et al., 1984).

An alternative interpretation of the broad gustatory focus of caloric alliesthesia seen in Experiment 1, however, is also possible. Oral infusions of water occurred for most rats in a context where infusions of sucrose or sucrose/quinine already had been experienced (since the order of taste presentation was random). The palatability of water can be influenced by associative experience with exteroceptive cues that have been paired with sweet or bitter tastes (Delamater, et al., 1986).

Conditioned shifts in palatability, elicited by associative cues, can interact with physiological state to produce a "conditioned alliesthesia": an affective shift in the response to the conditioned stimulus or context that only appears during particular physiological states (Booth, 1985; Berridge \& Schulkin, 1989). It is conceivable that the shifts in water palatability observed here depended upon a conditioned association with the taste of sucrose that had been delivered previously in the same chamber. Such an association between sucrose and the chamber might have interacted with physiological state to influence the perceived palatability of water delivered in that chamber. It would be interesting to examine the effects of caloric alliesthesia upon water palatability in rats that had never experienced sucrose infusions, in order to know which of these interpretations is correct. 
Relative magnitudes of hedonic suppression by caloric and sensory-specific satiety

Hedonic taste reactivity was reliably suppressed by caloric satiety. The absence of change in aversion to the quinine/sucrose mixture indicated that hedonic suppression was a specific affective change, and not a consequence of reduced sensorimotor arousal. A reduction of sensorimotor arousal should have reduced both hedonic and aversive reactivity. Hedonic suppression by caloric satiety was enhanced further by the combination of caloric and sensory-specific satiety. The specificity of this additional suppression of hedonics to a particular stimulus indicates that it too was a specific affective change and was not due, for example, to motor "fatigue".

Of the two forms of satiety, physiological caloric satiety appeared to be the dominant determinant of hedonic suppression: it was detectable for every taste in both experiments, whereas the additional suppression by sensory-specific satiety reached a significant magnitude only for the taste of sucrose, and was masked by the strength of the caloric satiety effect for the taste of milk Experiment 2. The relative weakness of sensory-specific satiety in this experiment, however, may be due to the "supersatiety" procedure that was used to induce thorough caloric and sensoryspecific satiety.

Each rat set its own preferred "maximum intake" limit in this procedure: the milk or sucrose was continually infused into the mouth of the rat until the food was no longer accepted. Since no action was required on the part of the rat to obtain the food, high levels of consumption naturally resulted. Rats consumed an average of $30 \mathrm{ml}$ of milk or sucrose in less than $30 \mathrm{~min}$ during the satiety-induced infusion. In order for a human to achieve similar consumption (proportional to body weight) a $75 \mathrm{~kg} / 165 \mathrm{lb}$ person would need to consume approximately 7 liters or 2 gallons! Consumption on this scale (which might be better described as "gluttony" than as "satiety") exceeds the levels that have been used in studies of alliesthesia in humans. Perhaps if rats had to work for their food or if meal size were smaller (more comparable to meals that have induced sensory-specific satiety in studies of humans), sensory-specific satiety might have a greater influence relative to caloric satiety.

\section{Hedonic specificity of allesthesia}

Regardless of whether the change in taste affect was positive or negative, or whether the cause was caloric state or sensory-specific satiety, all shifts in affect observed in this study were restricted to changes in the hedonic dimension of palatability (Figure 7). Aversive evaluations were never altered. Aversion was unchanged by hunger or satiety even for quinine-adulterated sucrose in Experiment 1, which elicited a significant aversive response. Aversion was again unchanged in Experiment 2 even by the "supersatiety" combination of caloric plus sensory-specific satiety that strongly suppressed hedonics. Caloric and sensory-specific satiety appear to act upon the hedonic system of affect but not upon aversion, unlike other manipulations that change pleasure and aversion reciprocally together, such as associative taste-LiCl pairing or salt appetite (Grill \& Norgren, 1978; Berridge, et al., 1984).

At first glance, the assertion that hunger and satiety alter taste pleasure exclusively may appear to conflict with the report by Cabanac \& Lafrance (1990) of enhanced aversive reactivity to sweetness after gastric infusion of glucose solutions. However, two considerations concerning aversion and satiety should be kept in mind. The first concerns the difference in the measurement of aversion between these two studies. 
In the study by Cabanac \& Lafrance (1990), the passive dripping of a taste solution from the mouth was included as an aversive response. The present study, by contrast, included only active aversive responses (e.g. gaping, headshaking, etc.) and did not include passive drip. The inclusion of passive drip as a measure is a legitimate method of discriminating active ingestion from rejection of a taste. But even an anesthetized animal "rejects" in this passive sense: this measure does not discriminate between rejection caused by active aversion versus rejection caused by mere cessation of ingestion. Although passive drip is a form of rejection that often accompanies active aversive reactions, passive drip by itself is ambiguous and has been argued to be "a response to taste that is neither strongly ingestive nor strongly aversive (i.e. a neutral response)" (p. 566, Berridge \& Grill, 1983). The results of Cabanac \& Lafrance (1990) clearly demonstrate a reduction of positive hedonics and of ingestion after gastric glucose intubation. It is difficult to know whether their results also imply an enhancement of active aversion, however, unless active aversive responses can be assessed separately.

The second issue regarding the interpretation of aversive changes in alliesthesia concerns the potential of gastric infusions for producing gastrointestinal distress. Nutrients that are delivered in excessive quantity or concentration may carry consequences that extend beyond satiety (Booth, 1985). Malaise or distress also might ensue from a gastric infusion, depending upon the quantity, rate, and content of the infusion. The possibility that gastric infusions cause gastrointestinal distress, and induce gustatory aversion as a consequence secondary to distress, complicates the interpretation of taste reactivity. Can one be certain that an increase in aversion after gastric infusion is due to satiety and not to gastrointestinal distress? Although overall aversion was not enhanced by gastric intubation in the present study, two rats did show marked aversive reactions to tastes after intubation. Enhanced aversion was never seen after voluntary ingestion of mash, sucrose, or milk, by contrast, supporting the argument that gastric infusions have the potential to induce aversion by means other than satiety.

With these considerations in mind, the results of the present study indicate that the change in taste affect produced by ordinary caloric and sensory-specific satiety is restricted to the hedonic dimension of palatability so long as gastrointestinal distress factors are excluded. Unidimensional hedonic suppression occurred after voluntary feeding, after "supersatiating" oral infusions, and after benign intubation of a milk diet. Unidimensional hedonic enhancement occurred after $48 \mathrm{~h}$ of food deprivation.

An implication of the hedonic exclusiveness of these affective changes is that normal satiety does not lie on a psychological continuum with aversion. Satiety does not induce a "state-dependent aversion" for the taste of food (merely a statedependent avoidance). Instead, satiety and aversion appear qualitatively distinct. Satiety induces affective shifts only on the hedonic dimension (Figure 7). True aversion, on the other hand, uniquely constitutes its own affective system. The failure of hunger or satiety to shift aversion itself, however, does not imply that these physiological states cannot modulate the influence of aversion upon the appetitive choice of what to ingest (Jacobs, 1967; Booth, 1972).

\section{Appetite without affect}

A separate point concerning taste pleasure and hunger is that hedonic enhancement was induced only after $48 \mathrm{~h}$ of food deprivation, and not after $24 \mathrm{~h}$ of deprivation. This result replicates Breslin \& Grill's (1988) report that $24 \mathrm{~h}$ food 
deprivation does not change affective reactions to sweetness. Although the failure of a 24-h fast to modulate taste affect is a mere "negative result", its replication demands that it be given serious attention. Such failures to induce alliesthesia after $24 \mathrm{~h}$ food deprivation imply that the appetite evoked by "moderate" fasts is mediated in a way that does not depend upon the direct hedonic enhancement of taste. In a similar phenomenon, feeding elicited by electrical stimulation of the lateral hypothalamus has been argued to be mediated by the activation of a non-hedonic "incentive attribution" component of appetite (Berridge \& Valenstein, 1991). Mild food deprivation might also activate an "incentive attribution" component of appetite, which evokes feeding without enhancing taste affect.

\section{Conclusion}

This study of natural affective reactions to taste supports the demonstrations by Cabanac, Rolls, Rolls, and their colleagues of changes in food affect produced by hunger, caloric satiety and sensory-specific satiety. In the case of taste affect, human subjective reports of modulation do appear to reflect true changes in basic affective processes. Yet it also appears that self-report has not captured the precise unidimensional nature of these affective changes. The distinction between changes on the hedonic and aversive dimensions of palatability has not appeared in human introspection measures of palatability changes. The results of this study, however, suggest that changes in food affect produced by hunger and satiety are restricted to the hedonic dimension (Figure 7).

It is not clear whether human reports fail to distinguish between hedonic and aversive shifts because the questions asked of human subjects have not yet been posed in a way that would allow dissociation of positive and negative affect, or whether for human conscious introspection a hedonic increase is simply indistinguishable from an aversive decrease. If the latter is true then, as Wundt argued a century ago (1904 1874), it may be that shifts in positive and negative sensory affect appear in consciousness always to be coupled reciprocally to each other (regardless of whether their mechanisms are coupled or not). If so, perhaps the underlying preconscious generation of pleasure and aversion are carried out separately, but are averaged or merged together by the processes of self-monitoring that give rise to conscious awareness of affect.

\section{REFERENCES}

Bedard, M. \& Weingarten, H. P. (1989) Postabsorptive glucose decreases excitatory effects of taste on ingestion. American Journal of Physiology, 250, 1142-1147.

Bem, D. J. \& McConnell, H. K. (1970) Testing the self-perception explanation of dissonance phenomena: On the salience of premanipulation attitudes. Journal of Personality and Social Psychology, 14, 23-31.

Berridge, K. C., Flynn, F. W., Schulkin, J. \& Grill, H. J. (1984) Sodium depletion enhances salt palatability in rats Behavioral Neuroscience, 98, 652-660.

Berridge, K. C. \& Grill, H. J. (1983) Alternating ingestive and aversive consummatory responses suggest a two-dimensional analysis of palatability in rats. Behavioral Neuroscience, $97,563-573$.

Berridge, K. C. \& Grill, H. J. (1984) Isohedonic tastes support a two-dimensional hypothesis of palatability. Appetite, 5, 221-223.

Berridge, K. C. \& Treit, D. (1986) Cholordiazepoxide directly enhances positive ingestive reactions in rats. Pharmacology, Biochemistry and Behavior, 24, 217-221. 
Berridge, K. C. \& Valenstein, E. S. (1991) What psychological process mediates feeding evoked by electrical stimulation of the lateral hypothalamus? Behavioral Neuroscience, 105, 3-14.

Berridge, K. C., Venier, I. L. \& Robinson, T. E. (1989) A taste reactivity analysis of 6-OHDA induced aphagia: Implications for arousal and anhedonia hypotheses of dopamine function. Behavioral Neuroscience, 103, 36-45.

Booth, D. A. (1972) Taste reactivity in starved, ready to eat, and recently fed rats. Physiology and Behavior, 8, 901-908.

Booth, D. A. (1985) Food-conditioned eating preferences and aversions with interoceptive element: conditioned appetites and satieties. Annals of the New York Academy of Sciences, 443, 22-41.

Booth, D. A. (1987) Cognitive experimental psychology of appetite. In R. A. Boakes, D. A. Popplewell \& M. J. Burton (Eds.). Eating Habits. Pp. 175 209. New York: Wiley.

Breslin, P. \& Grill, H. (1988) A stimulus-response analysis of ingestive taste reactivity. Neuroscience Abstracts, 14, 360 .

Cabanac, M. (1971) Physiological role of pleasure. Science, 173, 1103-1107.

Cabanac, M. (1979) Sensory pleasure. Quarterly Review of Biology, 54, 1-29.

Cabanac, M., Duclau, R. \& Spector, N. H. (1971) Sensory feedback in regulation of body weight: is there a ponderostat? Nature, 229, 125-127.

Cabanac, M. \& Fantino, M. (1977) Origin of olfacto-gustatory alliesthesia: intestinal sensitivity to carbohydrate concentration. Physiology and Behavior, 18, 1039-1945.

Cabanac, M. \& Lafrance, L. (1989) Gustatory alliesthesia in rat, Appetite, 12, 201.

Cabanac, M. \& Lafrance, L. (1990) Postingestive alliesthesia: the rat tells the same story. Physiology and Behavior, 47, 539-543.

Clifton, P. G., Burton, M. J. \& Sharp, C. (1987) Rapid loss of stimulus-specific satiety after consumption of a second food. Appetite, 9, 149-156.

Cohen, A. R. \& Zimbardo, P. G. (1969) Dissonance and the need to avoid failure. In P. G. Zimbardo (Ed.), The cognitive control of motivation. Glenview, Illinois: Scott, Foresman, pp. 23-41.

Delamater, A. R., LoLordo \& Berridge, K. C. (1986) Control of fluid palatability by extroceptive Pavlovian Signals. Journal of Experimental Psychology: Animal Behavior Processes, 12, 143-152.

Fantino, M. (1984) Role of sensory input in the control of food intake. Journal of the Autonomic Nervous System, 10, 347-358.

Giza, B. K. \& Scott, T. R. (1983) Blood glucose selectively affects taste-evoked activity in rat nucleus tractus solitarius. Physiology and Behavior, 31, 643-650.

Goethals, G. R. \& Reckman, R. F. (1973) The perception of consistency in attitudes. Journal of Experimental Social Psychology, 9, 491-501.

Grill, H. J. \& Berridge, K. C. (1985) Taste reactivity as a measure of the neural control of palatability. In J. M. Sprague \& A. N. Epstein (Eds.), Progress in psychobiology physiological psychology (Vol. 11). New York: Academic Press. Pp. 1-61.

Grill, H. J. \& Miselis, R. R. (1981) Lack of ingestive compensation to osmotic stimuli in chronic decerebrate rats. American Journal of Physiology, 240, R81-86.

Grill, H. J. \& Norgren, R. (1978) Chronic decerebrate rats demonstrate satiation but not bait shyness. Science, 201, 267-269.

Hetherington, M., Rolls, B. J. \& Burley, V. J. (1989) The time course of sensory-specific satiety. Appetite, 12, 57-68.

Jacobs, H. L. (1967) Sensory and metabolic regulation of good intake: thoughts on a dual system regulated by energy balance. In Proceedings of the VIIth International Congress of Nutrition. Pp. 17-29. Oxford: Pergamon Press.

Le Magnen, J. (1956) Hyperphagie provoqee chez le rat blanc par l'alteration du mécanisme de satiété peripherique. Compte Rendus des Séances de la Société de Biologie, Paris, 153, $32-34$.

Moskowitz, H. R., Kumraiah, V., Sharma, K. N., Jacobs, H. L. \& Sharma, S. D. (1976) Effect of hunger, satiety and glucose load upon taste intensity and taste hedonics. Physiology and Behavior, 16, 471-475.

Nisbett, R. E. \& Schachter, S. (1966) Cognitive manipulations of pain. Journal of Experimental Social Psychology, 2, 227-236.

Nisbett, R. E. \& Wilson, T. D. (1977) Telling more than we can know: Verbal reports on mental processes. Psychological Review, 84, 231-259. 
Rolls, B. J. (1985) Experimental analyses of the effects of variety in a meal on human feeding. American Journal Clinical Nutrition, 42 (Suppl), 932-939.

Rolls, B. J., Rolls, E. T., Rowe, E. A. \& Sweeney, K. (1981) Sensory-specific satiety in man. Physiology and Behavior, 27, 137-142.

Rolls, E. T., Murzi, E., Yaxley, S., Thorpe, S. J. \& Simpson, S. J. (1986) Sensory-specific satiety: food-specific reduction in responsiveness of ventral forebrain neurons after feeding in the monkey. Brain Research, 368, 79-86.

Rolls, E. T., Rolls, B. J. \& Rowe, E. A. (1983) Sensory-specific and motivation-specific satiety for the sight and taste of food and water in man. Physiology and Behavior, 30, 185-192.

Schachter, S. \& Singer, J. E. (1962) Cognitive, social and physiological determinants of emotional state. Psychological Review, 69, 379-399.

Schulkin, J. (1982) Behavior of sodium deficient rats: The search for a salty taste. Journal of Comparative and Physiological Psychology, 96, 628-634.

Stellar, E. (1982) Brain mechanisms in hedonic processes. In D. W. Pfaff (Ed.), The Physiological Mechanisms of Motivation. Pp. 377-407. New York: Springer-Verlag.

Treit, D., Spetch, M. L. \& Deutsch, J. A. (1982) Variety in the flavour of food enhances eating in the rat: a controlled demonstration. Physiology and Behavior, 30, 207-211.

Wundt, W. (1904) Principles of physiological psychology. Translated by E. B. Titchener from the 5th edition of Grundzuge der physiologischen Psychologie, New York: Macmillan.

Young, P. T. (1948) Appetite, palatability, and feeding habit: A critical review. Psychological Bulletin, 45, 289-320.

Young, P. T. (1959) The role of affective processes in learning and motivation. Psychological Review, 66, 1104-1125.

Young, P. T. \& Schulte, R. H. (1963) Isohedonic contours and tongue activity in three gustatory areas of the rat. Journal of Comparative and Physiological Psychology, 56, 465-475.

Received 17 January 1990, revision 6 July 1990 